\title{
Green Intellectual Capital Factors Leading to Business Sustainability
}

\author{
Kittisak Jermsittiparsert ${ }^{1, *}$ \\ ${ }^{1}$ College of Innovative Business and Accountancy, Dhurakij Pundit University, Bangkok, Thailand
}

\begin{abstract}
Today the impact of green intellectual capital on organizational sustainability have to be studied because of rising environmental concerns. There are three components of the green intellectual capital (GIC) which include green relational capital (GRC), green human capital (GHC) and green structural capital (GSC). This study fundamentally related to GIC three dimensions and business sustainability. Data from 238 SMEs in Thailand were collected and analyzed through PLS-PM method. Findings discovered that GHC does not have any influence on sustainability, but GSC and GRC are significantly related with sustainability of businesses.
\end{abstract}

\section{Introduction}

To academicians and professionals, sustainability development has become a matter of concern. There are wide-ranging discussions and debates on the definitions of the value of sustainability development and the means to it is omnipresent. Business economic gains have increased global wealth and living conditions which contribute directly or indirectly to the degradation of the ecosystem and social injustice. New work by [1] has shown that there are several ecological damages with an average of sixty per cent worldwide losses of environments. If this is not addressed, environmental challenges of the world will start to escalate. Nonetheless, several companies argue that their business activities do not cause environmental pollution and see it as the problem that is overlooked. In fact, the concept of sustainability did not apply to all organizations. Business conditions are now distinct with resource limits, higher technology prices, new emerging markets and challenges to traditional models [2]. In reaction to the destruction of natural surroundings and its adverse effect on the environment, humans, community well-being, and economic development, the word "sustainability" was first used to deal with above-listed figures. Accordingly, [3], states that sustainability is part of an expansion, which satisfies the requirements of current generation without undermining the requirements of the forthcoming generation that are commonly applied to these combined findings in literature: environmental, social and economic. It has become a compulsory subject to be explored in depth, as different states, cities and organizations have started to follow recent and various direction. Scholars are vigorously sought new solutions to reduce the negative environmental impact of human activities.

\footnotetext{
*Corresponding author: kittisak.jer@dpu.ac.th
} 
Accordingly, studies related to green business such as, green HRM, green supply chain, green innovation, green purchasing and low-carbon discharge [4-8) and are developing gradually. In addition, [9] proposed to invest in IC (intellectual capital) linked to the environment, recognized as a GIC which offers competitive benefits as well as management of the environment. IC relates to the intangible reserves on the part of the organization that are very important in comparison to tangible reserves. Green intellectual capital is unfamiliar to both practitioners and academics. The above-mentioned sustainable issues are viable solutions to green intellectual capital. Green intellectual capital is a viable solution for the sustainability issues mentioned above. GIC is related to tangible knowledge or reserves linked to innovation or protection of the environment [9]. GIC has 3 different dimensions, which we have mentioned above: green structural capital (GSC) green relational capital (GRC) and green human capital (GHC). Within the context of this study, this research is important. Diverse opinions empirically and theoretically have recognized SMEs' considerable role in economic growth across countries around the world, like Thailand. In particular, [9] states that GIC in SME's had less attention than larger organizations.

\section{Literature Review}

\subsection{Business Sustainability}

In a Report published in the 1972 Gunilla, the word "sustainability growth" was first introduced [10]. The research was then reviewed in 1987 by the Brund land report and subsequently published in 1989 by the World Environment and Development Commission (WEDC) [11]. Consequently, the report described sustainable growth without disregarding the requirements of forthcoming generations. The report says that the foundation of sustainable development has two core concepts: the requirements for the disadvantaged (poor) and the ecological constraint required for meeting forthcoming requirements. Elkington (1994), who developed the three-fold baseline is another contributor to the area, it is a structure linked to sustainability that includes 3 things: planet, people and profit are famous as three Ps [12].

The phrase 'TBL' and 'sustainability' often used interchangeably are a sustainability system that contains three sections. Sustainability is not specified for single definition [13]. With more than 70 different definitions, [14] of this concept supported by a large number of scientists [15-16). Sustainability was described as an organizational bond with earth by [17], which is the shelter of every stakeholder. Sustainability provides benefits to its stakeholders, enhances the lives and environmental security of those with whom they associate. The sustainability three dimensions have in one aspect been closely linked to improvements. On the other hand, we emphasized that sustainability depends heavily towards lessening the issue of environment, sustainability simultaneously improves wealth and health is mythical. [18] described sustainability as an organizational-driven proactive approach, thus considering the requirements of the forthcoming generation, to meet the goals of its stakeholders. Sustainability is aimed at achieving three cultural, social, and environmental performance goals simultaneously [19]. The word sustainability has been argued by [20] for maintaining and preserving people's well-being. Sustainability also concentrates not only on the three dimensions alluded to above, but also on CSR and moral problems [21]. However, [22] said that profits are higher than moral and social responsibility issues in companies. Previous scholars believe that if companies are based on competitiveness, their efforts would be increased to reduce waste while maximizing benefit, 
and limited resources recycled and reuse would boost fiscal and GDP efficiency, it is also the environmental goals of sustainability [23].

Even though, sustainable performance seeks to maintain a balance of multi-dimensional performance, its significance is incompatible. Consequently, many abstract and theoretical concepts are correlated with the misconceptions of the term [24]. In the report, business sustainability refers to the organizational goal of benefit and social development in the light of ecological characteristics.

\subsection{Green Intellectual Capital}

Instead of using physical assets to achieve a better result, recently the world relies towards unquantifiable resources [25]. Intangible assets are required to ensure survival of a company, promote innovation, and improve competitive advantage [26-27]. Intellectual properties are also termed as intellectual capitals (IC). Higher IC organizations should profit more than low IC organizations [28]. The scholar recently proposed that intellectual capital as a witness to address small and medium-sized enterprises' vulnerability ([29]. In 1969 John Keneth Galbraith's coined the word "IC" with Tom Stewert to popularize the idea in 1991 [30]. Intellectual capital definition holds a great deal of debate and resulted in many books in different subjects. IC is the number of belongings everybody knows in companies that ensure a competitive market advantage or the total collective information inventory, experience, intellectual property rights, technologies, customer relations, team communication systems, organizational competence and learning and brands which can generate organizational value.

The alternative concept of intellectual capital is the information that can be translated into organization, which includes innovations, inventions, design, marks, computer programs and patents. Intellectual capital is "any tool, which is completely or partly monitored and contributes to the development of value for the organization [31]. While the literature on the meaning of IC has been proliferating, the IC meanings described are almost metaphorically identical. It can be inferred from the above definitions that IC defines all of an organization's intangible resources, in fact, there have constantly been publications from various perspectives explaining IC principles. Nevertheless, it is unusual for academics and practitioners to include IC in environmental principles (known as GIC).

[9], presented the GIC definition as the first researcher. [32], later identified GIC as an unimportant area and therefore its somewhat restricted meanings in management literature. [9] has defined the GIC as an amount of unquantifiable reserves, expertise, relationships and information related to the ecological revolution and green protection of a limited number of meanings. Liu (2010) defines GIC as the synthesis of the organizations' ability to improve their competitive advantage and green awareness.

[34] reported that in today's business world the idea of environmentalism has become mainstream with a view to reducing ecological influences and meteorological conditions change, thus additionally encouraging companies to establish green modernization. Growing market understanding of environmental issues has led companies to find innovative ways to meet environmental trends by managing the environment and improving their green picture [35]. In [35], the organization has to report that GIC supports companies comply with stringent global mental standards, value creation and fulfilling high environmental demands of customers.

Three elements of clarification have been taken into account for this report, including the GRC, GSC and GHC as recommended by [9]. [32] found in the limited papers that both green relational capital and green structural capital in large manufacturing companies have a significant impact towards green HRM. [4] found an unsupported relationship of sustainable human capital towards green innovation. Meanwhile, observed that 
organizational knowledge has a significant correlation towards corporate sustainable development. The positive links between GIC and financial performance have also been endorsed [36]. On the other hand, [37] found that the green competitive edge had significant correlation with two GIC classifications, green relational capital and green structural capital.

However, [38] have discovered that the GIC component of the green social capital aspect was considered relevant with the innovations of sustainable goods but opposed to green organization capital. The authors have disclosed the significant influence of GIC towards corporate social responsibility and environmental awareness [39]. [35] found that the connection among competitive advantage ecological awareness is mediated by green intellectual capital. [9] finally concluded that GIC led towards the competitive advantage of the organization.

\subsection{Hypothesis Development}

\subsubsection{Relationship between $G H C$ and BS}

Human capital is believed to grow as workers gain new knowledge, skills and expertise. It helps employees to work effectively, reduce policy mistakes, improve job efficiency and accomplish improved results. The environmental dimension cannot now be overlooked by an entity. The position of GHC towards BS is therefore important to explore. The proof of a strong GHC effect on green human resources management has been identified [32]. Likewise, the GRC positive impact on financial performance has been endorsed by [36]. In the meantime, the correlation between GHC and green innovation success has also been verified. Study has reported that green intellectual capital assists organizations in dealing with stringent international environmental regulations, building corporate interest and reacting to high environmental customer needs. [40] further stated that the contribution of human capital to sustainability is significant. Nevertheless, the association among GHC and BS has not still been explored through empirical research. From the above discussion, the following hypothesis has been developed:

H1: GHC and BS are significantly related.

\subsubsection{Relationship Between GSC and BS}

Prior scholars acknowledged the importance of improving organizational performance through structural capital [41-42]. Several previous studies have shown that green structural capital has significant positive influence on the outcomes of performance. The relationship among GSC and competitive advantage was noticed by [9] and [37]. A study reported that the significant influence of green structural capital on skills and commitments of environment. Green organizational capital has a positive correlation with green product innovation [38]. The significant impact of green structural capital on the financial performance has been described by [36]. The linkage between green organization's culture and green innovation were shown by [43]. Furthermore, it is argued that GSC is necessary for sustainable development. Nevertheless, the relationship among GSC and BS has not yet been investigated by empirical research. As such, the following research assumes:

H2: GSC and BS are significantly related. 


\subsubsection{Relationship Between GRC and BS}

Indeed, many manufacturing organizations are establishing close ties with their suppliers, to exploit their expertise and knowledge to faster build innovative goods on less price, impacting the organization's achievements positively [44]. Effective coordination with others will also act as a basis to achieve the projected mental goals. The author noted that a more sustainable society has emerged through ties between organizations, government and other institutions [45]. In his present research author argued that, secure green partnerships allow exchange with environmental consciousness between business parties which alternatively, reduces environmental uncertainty [46]. In addition, in establishing good environmental practices, the scholars stressed towards the significance of interacting policies in the organizations. Additionally, [47] concluded that the exchange of information and cooperation are important when a sustainable approach is being implemented. Many past studies have shown that green relational capital has a significant positive effect on performance. A significant correlation exists between GRC and competitive advantages as suggested by [9] and [37]. Similarly, a significant and positive relationship between GRC and the ecological ability and engagement practices. GRC's significantly impact on green human resources management was observable by [32]. However, study argued that GRC is essential for sustainable development [40]. But the association among GRC and BS was not explored by empirical research. As such, the analysis assumes:

H3: GRC and BS are significantly related.

\section{Research Methodology}

\subsection{Theoretical Background}

In this analysis two key theories were used: Intellectual Capital-based View (ICBV) and Natural Resource Based View (NRBV). NRBV concluded that environmental capital as well as capability are important for the present and future competitive advantage, NRBV states, on the other hand, that RBV ignores the connection between the nature and the organization [48]. In addition, intangible assets are the organization's strategically valuable resources and capabilities. Nevertheless, the unquantifiable properties accumulated by scholars are difficult to measure. They attempted by developing intellectual capital models, known as ICBV [49], to solve these bottlenecks in intangible measurements. In general, ICBV focused on intangible or intellectual resources calculation that classified them in three categories: such as green human capital, green rational capital and green structural capital. The study aims to connect these two hypotheses in order to conceptualize the immaterial resources, by integrating the green with green intellectual capital and contributing to corporate sustainability.

\subsection{Study Measurements}

GIC consists of 3 dimensions namely, GRC, GSC and GHC developed by [35] with a total of eighteen (18) number of items. The scale was measured with a Likert type scale of 7 points ranging from 1 to 7 which indicates $1=$ strongly disagree to $7=$ strongly agree. [50] scale has been taken to measure the business sustainability. The respondents have evaluated their performance in the company with a total of 22 items on three main aspects, namely environmental, social and economic. 


\section{Research Results}

\subsection{Measurement Model}

Business sustainability factor was treated as a higher order construct. Thus, the reliability and validity of the lower order construct were tested. Table 1 has shown all the concerns related to the measurement model, such as composite reliability, outer loading and average variance extracted. All items have a composite reliability of more than 0.7 and all variables have AVE values of more than 0.5. Furthermore, the discriminating validity of the measurement model for each variable (lower order) was checked for differences. The values of HTMT by [51] as shown in Table 2 met the threshold value of not more than 0.85 [52], indicating that after removing 7 items the model reached discriminant validity.

Table 1. Outer Loadings, CR and Average Variance Extracted

\begin{tabular}{|c|c|c|c|c|c|}
\hline $\begin{array}{c}\text { Lower Order } \\
\text { Constructs }\end{array}$ & Higher Order Constructs & Items & Loading & $\begin{array}{l}\text { Composite } \\
\text { Reliability }\end{array}$ & $\begin{array}{c}\text { Average } \\
\text { Variance } \\
\text { Extracted }\end{array}$ \\
\hline \multirow[t]{5}{*}{ GreHC } & & GreHC_1 & 0.752 & 0.863 & 0.629 \\
\hline & & GreHC_2 & 0.844 & & \\
\hline & & $\mathrm{GreHC}_{-}^{-} 3$ & 0.830 & & \\
\hline & & $\mathrm{GreHC}_{-}^{-} 4$ & 0.752 & & \\
\hline & & GreHC_5 & 0.866 & & \\
\hline \multirow[t]{8}{*}{ GreSC } & & GreSC_1 & 0.877 & 0.834 & 0.673 \\
\hline & & GreSC_2 & 0.785 & & \\
\hline & & $\mathrm{GreSC}_{3}^{-} 3$ & 0.763 & & \\
\hline & & GreSC_4 & 0.872 & & \\
\hline & & GreSC_5 & 0.821 & & \\
\hline & & GreSC_6 & 0.945 & & \\
\hline & & GreSC_7 & 0.870 & & \\
\hline & & GreSC_ 8 & 0.856 & & \\
\hline \multirow[t]{6}{*}{ GreRC } & & GreRC_1 & 0.041 & 0.844 & 0.781 \\
\hline & & GreRC_2 & 0.805 & & \\
\hline & & GreRC_3 3 & 0.819 & & \\
\hline & & GreRC_4 & 0.807 & & \\
\hline & & GreRC_5 & 0.840 & & \\
\hline & Green_Intellectual_Capital & & & & \\
\hline \multirow[t]{6}{*}{ EcoS } & & EcoS_1 & 0.723 & 0748 & 0.517 \\
\hline & & Ecos_2 & 0.741 & & \\
\hline & & EcoS_3 & 0.731 & & \\
\hline & & EcoS_4 & 0.757 & & \\
\hline & & EcoS_5 & 0.877 & & \\
\hline & & EcoS_6 & 0.865 & & \\
\hline \multirow[t]{6}{*}{ SocS } & & SocS_1 & 0.739 & 0.907 & 0.605 \\
\hline & & SocS_2 & 0.721 & & \\
\hline & & SocS_3 & 0.718 & & \\
\hline & & SocS_4 & 0.808 & & \\
\hline & & SocS_5 & 0.752 & & \\
\hline & & SocS_6 & 0.770 & & \\
\hline \multirow[t]{6}{*}{ EnvS } & & EnvS_1 & 0.809 & 0.804 & 0.617 \\
\hline & & EnvS_2 & 0.835 & & \\
\hline & & EnvS_3 & 0.783 & & \\
\hline & & EnvS_4 & 0.804 & & \\
\hline & & EnvS_5 & 0.935 & & \\
\hline & & EnvS_6 & 0.809 & & \\
\hline
\end{tabular}




\begin{tabular}{ccccc} 
& EnvS_7 & 0.709 & & \\
& EnvS_8 & 0.784 & & \\
& EnvS_9 & 0.827 & & \\
& EnvS_10 & 0.740 & & \\
Business_Sustainability & SocS_1 & 0.898 & 0.867 & 0.697 \\
& EcoS_1 & 0.794 & & \\
& EnvS_1 & 0.913 & & \\
\hline
\end{tabular}

Table 2. Discriminant Validity

\begin{tabular}{ccccc}
\hline Variables & BS & GHC & GRC & GSC \\
\hline BS & & & & \\
GHC & 0.723 & & & \\
GRC & 0.703 & 0.837 & & \\
GSC & 0.790 & 0.730 & 0.704 & \\
\hline
\end{tabular}

\subsection{Structural model}

The structural model shows the connection between the variables. The relationship between path coefficients of the structural model is +1 to -1 . The higher the value of path coefficient and closer to 1 , the strong the positive relation. Whereas, the value of path coefficient which is nearer to 0 indicates a weak relation as suggested by [53]. Findings indicated, the connection between GRC $>$ BS $(\beta=.665, \mathrm{p}<0.05)$ and GSC $>$ BS $(\beta=.348, p<$ $0.05)$, whereas $\mathrm{GHC}>\mathrm{BS}(\beta=.047, \mathrm{p}>0.05)$ are significantly and positively associated to business sustainability. $\mathrm{H} 2$ and $\mathrm{H} 3$ have therefore been supported although $\mathrm{H} 1$ has not been supported. As proposed by [53], by using bootstrapping technique with 5000 resamples, coefficient of determination, $\beta$ values and $t$-value were utilized to assess the satisfactory level of the structural model. Moreover, Table 3 has showed all the relevant result of the structural model.

Table 3. Hypothesis Description

\begin{tabular}{ccccccccc}
\hline Constructs & B & SE & $\begin{array}{c}\text { Lower } \\
\text { Limit }\end{array}$ & $\begin{array}{c}\text { Upper } \\
\text { Limit }\end{array}$ & f2 & $\begin{array}{c}\text { t } \\
\text { value }\end{array}$ & $\begin{array}{c}\text { P } \\
\text { value }\end{array}$ & Findings \\
\hline GRS $>$ BS & .665 & .89 & 0.331 & 0.464 & 0.132 & 2.375 & 0.000 & Supported \\
GSC $>$ BS & .348 & .073 & 0.308 & 0.554 & 0.153 & 2.938 & 0.002 & Supported \\
GHC $>$ BS & .047 & .097 & 0.152 & 0.099 & 0.009 & 0.071 & 0.345 & Unsupported \\
\hline
\end{tabular}

\section{Conclusion}

The GIC concept is a feasible solution for environmental concerns and for sustainable business growth. But this topic was fairly restricted to a few studies. This research therefore offers greater information on sustainability of companies and green intellectuals in Thai context with respect to small and medium-sized enterprises. Eventually, a strong understanding of environmental issues could inspire small and medium-sized manufacturing companies to adopt green strategies. It is important for firms' producers to invest in green intellectual resources and market sustainability. This research is the first step towards a sustainable market sustainability that could be replicated and repeated in future models.

The findings have led to three major conclusions. First, the results showed that the association among green human capital and business sustainability was insignificant. These 
result conflicts with previous research, such as those conducted by [32] and [34]. There could possibly be a number of reasons for the negligible relationship between GHC and BS. Many previous studies have demonstrated the lack and low level of environmental management priorities of SME organizations [54]. Therefore, the new concept of GHC tends to be ignored by most organizations, particularly SMEs; they are not fully embedding the era of environmental awareness. The educational programs will provide environmental knowledge in the enterprise's related to green human resources, to acquire the benefits of business prospects and to satisfy customer requirements.

Secondly, a positive relationship between GSC and BS has been found. The outcomes are based related to the outcomes of the prior study by [9] that shows a significant correlation between GSC and competitive advantage. In the same way, previous research has shown that structural capital has contributed to an organization's survival. The encouraging and positive results indicates the significant impact of the green structural capital towards business sustainability and was recognized by manufacturing SMEs. In order to support the cycle, sustainability is perceived to be essential for companies to meet new business challenges through GSC. New technology, structural capital improvements and environmental sustainability within organizations [55], are often needed to achieve a sustainability.

Thirdly, the study's findings have shown GRC to have a significant progressive effect towards business sustainability. Here the results are consistent with the previous study [9], which identified a major contribution from the GRC in diverse market outcomes [32]. In addition, the relationship of rational capital and sustainability were found by [56-57]. Results show that knowledge-sharing and cooperation are the foundation of ties between small and medium-sized companies and their stakeholders. The creation of the GRC is expected to be facilitated through a collective attitude. This approach helps businesses to pursue strategies for business sustainability in particular they are able to share the insights and advantages of business sustainability activities with their green rational capital aspects. Production companies should also use green rational capital to build a shared dialog with their partners to reduce environmental impacts and to deliver goods that are environmentally sound, thereby enhancing sustainability.

The research also helped to fill the gap in small and medium-sized enterprises. The experience of GIC and BS has therefore contributed to the current literature. Furthermore, this research made some theoretical insights in relation to both Natural Resource-Based View (NRBV) and ICBV. The NRBV suggests that in the coming years the policy and competitive advantage will rely on capacities to support an eco-sustainable economy. While, the ICBV focuses mainly on the information asset of organizations, known as a strategic source as a competitive edge. Very few scholars are currently researching the business sustainability environment. The researchers are still at an early stage that may be a potential path to business strategies.

\section{References}

1. M. Gong, A. Simpson, L. Koh, K. Tan, Resources, Conservation and Recycling, 128 (2018).

2. K. Sullivan, S. Thomas, M. Rosano, J. Clean. Prod., 174 (2018).

3. UN. Secretary-General, Report of the World Commission on Environment and Development: Our common future, (1987).

4. M. Aboelmaged, G. Hashem, J. Clean. Prod., 220 (2019).

5. C. Jabbour, A. de Sousa Jabbour, J. Clean. Prod., 112 (2016).

6. M. Ma, W. Cai, W. Cai, L. Dong, J. Clean. Prod., 222 (2019). 
7. A. Zaid, A. Jaaron, A. Bon, J. Clean. Prod., 204 (2018).

8. W. Zhang, C. Chai, Y. Song, Q. Fan, Y. Yang, Materials, 11 (2018).

9. Y. Chen, JBE, 77 (2008).

10. G. Almgren, Sustainable Entrepreneurship, (Springer, 2014).

11. R. Borim-de-Souza, Z. Balbinot, E. Travis, L. Munck, A. Takahashi, CCM, 22 (2015).

12. F. Montabon, M. Pagell, Z. Wu, JSCM, 52 (2016).

13. T. Galpin, J. Hebard, WJEMSD, 11 (2015).

14. R. Lozano, J. Clean. Prod., 16 (2008).

15. N. Habidin, S. Hashim, Z. Zainol, W. Mustaffa, S. Ong, N. Hudin, GMJSS, 11 (2017).

16. K. Owens, S. Legere, IJSHE, 16 (2015).

17. G. Svensson, B. Wagner, MEQAIJ, 22 (2011).

18. P. Bansal, M. DesJardine, SO, 12 (2014).

19. S. Sartori, F. Latrônico, L. Campos, AS, 17 (2014).

20. J. Meng, JMK, 35 (2015).

21. C. Raitu, B. Anderson, L. John, G. Narayanamurthy, WJSTSD, 12 (2015).

22. I. Stancu, D. Stancu, D. Dumitrescu, A. Tinca, AEJ, 17 (2015).

23. S. Dahlgaard-Park, J. Dahlgaard, M. Maletic, D. Maletic, J. Dahlgaard, B. Gomišcek, IJQSS, 7 (2015).

24. Y. Jabareen, EDS, 10 (2008).

25. L. Agostini, A. Nosella, R. Filippini, JIC, 18 (2017).

26. I. Berezinets, T. Garanina, Y. Ilina, JIC, 17 (2016).

27. B. Obeng, P. Robson, H. Haugh, ISBJ, 32 (2014).

28. M. Ahmad, N. Ahmed, IJLIC, 13 (2016).

29. C. Verbano, M. Crema, TASM, 28 (2016).

30. A. Serenko, N. Bontis, KPM, 11 (2004).

31. G. Roos, JIC, 18 (2017).

32. J. Yong, M. Yusliza, T. Ramayah, O. Fawehinmi, J. Clean. Prod., 215 (2019).

33. C. Liu, Proceedings of the $8^{\text {th }}$ International Conference on Supply Chain Management and Information (Hong Kong Polytechnic University, 2010).

34. Y. Chen, MD, 49 (2011).

35. C. Huang, F. Kung, MD, 49 (2011).

36. N. Erinos, Y. Yurniwati, Proceedings of the $1^{\text {st }}$ Padang International Conference on Economics Education, Economics, Business and Management, Accounting and Entrepreneurship, (Universitas Negeri Padang, 2018).

37. A. Firmansyah, Substansi, 1 (2018).

38. M. Delgado-Verde, J. Amores-Salvadó, G. Martín-de Castro, J. Navas-López, KMRP, 12 (2014).

39. C. Chang, Y. Chen, MD, 50 (2012).

40. C. Akhtar, K. Ismail, M. Ndaliman, J. Hussain, M. Haider, JMR, 7 (2015).

41. A. Sharabati, S. Jawad, N. Bontis, MD, 48 (2010).

42. Z. Wang, N. Wang, H. Liang, MD, 52 (2014).

43. M. Gürlek, M. Tuna, SIJ, 38 (2018). 
44. A. Walter, JBR, 56 (2003).

45. E. Niesten, A. Jolink, A. de Sousa Jabbour, M. Chappin, R. Lozano, J. Clean. Prod., 155 (2017).

46. P. Dickel, J. Hörisch, T. Ritter, J. Clean. Prod., 179 (2018).

47. V. Matinaro, Y. Liu, J. Poesche, J. Clean. Prod., 209 (2019).

48. S. Hart, AMR, 20 (1995).

49. K. Reed, M. Lubatkin, N. Srinivasan, JMS, 43 (2006).

50. W. Chow, Y. Chen, JBE, 105 (2012).

51. J. Henseler, C. Ringle, M. Sarstedt, (2015). JAMS, 43 (2015).

52. R. Kline, Principles and practice of structural equation modelling, (Guilford, 2015).

53. K. Hair, C. Hollingsworth, A. Randolph, A. Chong, IMDS, 117 (2017).

54. M. Moorthy, IJAREMS, 1 (2012).

55. M. López-Gamero, P. Zaragoza-Sáez, E. Claver-Cortés, J. Molina-Azorín, BSE, 20 (2011).

56. M. Massaro, J. Dumay, A. Garlatti, F. Dal Mas, JIC, 19 (2018).

57. P. Munyede, J. Contemp. Gov. Public Policy 2, 67 (2021) 